\title{
Editorial: Passing the baton
}

\author{
Diego De Leo and Jane Pirkis
}

\section{Diego De Leo}

After a renewal of the four-year term, my mandate as Editor-in-Chief of Crisis ended in July 2016.

Willingly, I have continued in my role for eighteen more months, until the search for a new editor was eventually finalised. It has been a long journey and a major commitment for me, but certainly I did not walked alone during these years. First of all, I need to express my gratitude to the International Association for Suicide Prevention, which honoured me by conferring me the editorship of the journal. It was certainly a great privilege and a big responsibility. It goes without saying that suicide, besides being the worst of all human tragedies, represents a kind of battlefield of different theories, approaches, viewpoints, religious perspectives, and ethical dilemmas. However, my editorship crossed five different executive boards of IASP and nobody ever interfered with my work; on the contrary, I was always supported in the management of the journal and felt appreciated for the efforts paid to its development. Nobody pressured me on any particular direction to give to the journal; no one claimed any space in terms of editorials or articles or a post in the Editorial Board. Many thanks, then, to all five IASP Executive Board Members that I crossed for such a desirable and impeccable behaviour.

In nearly ten years of editorship, the composition of Crisis Editorial Board changed remarkably. A few people retired, other members passed away. I cannot but think to Norman Farberow and Terry Maltsberger as great figures in the world of suicidology that are not any longer with us. I like to mention also the assistance gently provided to me by Bela Buda for several years. He is also missed by many of us.

All Editorial Board Members have been instrumental to the developments of Crisis and I am deeply grateful to all of them for this. A special mention has to go to my Associate Editors, first of all to Ad Kerkhof, who preceded me in the management of Crisis and who certainly did a lot in establishing the 
journal as one of the leaders in the area of suicide research and prevention. Then, Maria Oquendo and Ella Arensman have been my alter ego for many years and surely their importance as leading researchers has contributed to confer status and reputation to Crisis.

Apart from the members of the Editorial Board, my heartfelt thanks go to the many anonymous reviewers who have helped me so much in choosing and improving the quality of hundreds of papers published in the past decade by Crisis. Their contribution has been of paramount importance in securing competence, balance and appropriate selection of articles, which is now survived by less than twenty per cent of all submissions.

I have found in the publisher Hogrefe a great partner. Especially Robert Dimbleby and Juliane Munson have been fantastic travel mates along these past years. Timely, precise, open to innovations, they have been a central element to the success of the journal.

Griffith University has been incredibly generous in supporting the editorial responsibilities of Crisis all along my mandate, and I am surely not forgetting the unmatchable role of Wendy Iverson in assisting me with my editorial duties. Wendy will also assist the new Editor-in-Chief, transferring the invaluable knowledge acquired along nearly ten years and thus securing a very smooth transition.

I am not exaggerating if I say that the role of new Editor-in-Chief could not be represented better than by Professor Jane Pirkis. Jane is a well-established and prolific scholar in suicide research and prevention. With more than 250 peer-reviewed papers published and two decades of active presence in the international arena, she represents an excellent choice by the IASP committee devoted to the appointment of the new editor for Crisis. Currently, Jane is also the first IASP vice-president, with previous experience in the board of the association. This is a plus, since it has permitted her to acquire familiarity with virtually all problems related to the field of suicide prevention. 
A registered psychologist, Jane is the Director of the Centre for Mental Health in the Melbourne School of Population and Global Health at the University of Melbourne. She is a robust scientist, with a particular interest in evaluation of suicide prevention programs and mental health care initiatives. She is known worldwide for her particular research interest in suicide and the media. She was the recipient of the Lifetime Research Award by Suicide Prevention Australia in 2010. With Rory O'Connor, she co-edited the second edition of the International Handbook of Suicide Prevention (Wiley, 2016).

Apart from the many academic achievements and research projects, at the relation level Jane is the type of person that can make feel at home everybody. This is a rare quality, and this is my special wish for her and the future of Crisis: that the journal establishes itself as the common house of scholars and contributors from all parts of the world, and that cultural diversities may also be recognised as a powerful resource for teaching suicide prevention.

Good luck, Jane!

\section{Jane Pirkis}

I feel very privileged to be taking over as Editor-in-Chief from Diego De Leo. Diego became the Editor-inChief of Crisis in 2008, having been on the Editorial Board since 1990. He shared the role with Annette Beautrais until 2010, and then continued solo. He was visionary and was keen to see Crisis become the go-to journal for those working in suicide prevention. He actively set out to ensure that the journal would attract and publish the best studies in the field, ones that would significantly advance knowledge and influence policy and practice.

Diego's vision has certainly been achieved if standard metrics are anything to go by. On his watch, Crisis has gone from strength to strength. In 2010 the journal moved to six issues per year, as opposed to four, and in 2013 its volume was increased by a further $20 \%$ when it expanded to approximately 72 pages per 
issue. The journal's impact factor rose from 1.127 in 2008 to1.440 in 2016 (and its 5-year impact factor increased from 1.597 in 2010 to 2.400 in 2016). In 2016, articles in Crisis were cited a total of 1,318 times.

Perhaps more importantly, there is objective evidence that the journal is having its desired impact at the policy and practice level. By way of example, the World Health Organization (2014) report entitled Preventing Suicide: A Global Imperative- arguably the most influential guide to suicide prevention activity internationally - cites five key articles from Crisis in its reference list (Bohanna \& Wang, 2012; Coveney, Pollock, Armstrong, \& Moore, 2012; Jansen, Buster, Zuur, \& Das, 2009; Luxton, June, \& Comtois, 2013; Mishara \& Martin, 2011).

Diego is one of the most respected senior suicide prevention researchers in the world. He has an enviable list of research outputs that includes over 350 peer-reviewed articles and 170 book chapters. His epidemiological work has furthered our understanding of suicidal behaviour among different cultural groups and among older people, and his large scale, multi-site intervention studies have improved our knowledge of effective suicide prevention strategies in different countries. His significant achievements have been recognised by numerous honours, including the International Academy of Suicide Research Morselli Medal (2017), the American Association of Suicidology's Louis I Dublin Award (2011), Suicide Prevention Australia's Lifetime Research Award (2007), and the International Association for Suicide Prevention's Stengel Award (1991). Each of these awards recognises outstanding contributions to the study of suicidal behaviour. With these credentials, it is not surprising that Diego was able to achieve so much success as Editor-in-Chief of Crisis. Diego led by example and was willingly supported by those in his extensive international network of suicide prevention researchers who keenly submitted some of their most outstanding manuscripts to the journal.

For my part, I am very pleased to be taking on the role of Editor-in-Chief because Crisis has a special place in my heart. I sent one of my first ever articles on suicide prevention to the journal as a 'green' 
researcher in 2000, and was over the moon when it was accepted (Pirkis, Burgess, \& Dunt, 2000). Ad Kerkhof was the Editor-in-Chief at the time and encouraged me to submit another one, so I felt like I had really made it as a suicide prevention academic! I'm proud to say that to this day, that first article and two others that I published in Crisis later (Pirkis \& Blood, 2001; Vijayakumar, John, Pirkis, \& Whiteford, 2005) are among my six most highly cited articles.

My own vision for Crisis builds on Diego's. I'm keen to consolidate and leverage from the firm foundation that Diego has laid, and continue to maintain the journal's positive trajectory. I'd like it to reflect on where we're at now in suicide prevention, and showcase the cutting-edge research that can help us get to where we want to be. We know a lot more about what works and what doesn't work in suicide prevention than we did 10 years ago, but there is still a great deal to be learned. We're overcoming some of the definitional, ethical, methodological and practical issues that have traditionally best suicide prevention research, but we haven't nailed them yet. And we're better than we used to be about taking into account the perspectives of those with lived experience of suicide, but there is still definitely room for improvement.

Diego has worked tirelessly to make Crisis the success it is today, and I am conscious that I have big (stylish Italian leather) shoes to fill. I am delighted that Diego will continue to play an important role as Editor Emeritus and will remain on the Editorial Board, and would like to thank him sincerely for everything he has done for the journal in the past nine years.

Onward and upward!

\section{References}

Bohanna, I., \& Wang, X. (2012). Media guidelines for the responsible reporting of suicide: A review of effectiveness. Crisis, 33(4), 190-198. 
Coveney, C., Pollock, K., Armstrong, S., \& Moore, J. (2012). Callers' experiences of contacting a national suicide prevention helpline. Crisis, 33(6), 313-324.

Jansen, E., Buster, M., Zuur, A., \& Das, C. (2009). Fatality of suicide attempts in Amsterdam 19962005. Crisis, 30 (4), 180-185.

Luxton, D., June, J., \& Comtois, K. (2013). Can postdischarge follow-up contacts prevent suicide and suicidal behaviour? A review of the evidence. Crisis, 34(1), 32-41.

Mishara, B., \& Martin, N. (2011). Effects of a comprehensive police suicide prevention program. Crisis, 33(3), 162-168.

O'Connor, R. \& Pirkis, J. (2016). The International Handbook of Suicide Prevention. Wiley, Chichester.

Pirkis, J., \& Blood, R. W. (2001). Suicide and the media: Part 1. Reportage in nonfictional media. Crisis, 22(4), 146-154.

Pirkis, J., Burgess, P., \& Dunt, D. (2000). Suicidal ideation and suicide attempts among Australian adults. Crisis, 21(1), 16-25.

Vijayakumar, L., John, S., Pirkis, J., \& Whiteford, H. (2005). Suicide in developing countries (2): Risk factors. Crisis, 26(3), 112-119.

World Health Organization. (2014). Preventing Suicide: A Global Imperative. Geneva: World Health Organization. 